\title{
Estudo no Atletismo brasileiro: estruturas físicas, equipamentos esportivos e objetivos para o esporte
}

https://doi.org/10.11606/issn.1981-4690.v35i2p229-247

\section{Resumo}

Este estudo, quanto aos fins, é de caráter quali-quantitativo e, quanto aos meios, utiliza-se de pesquisa documental para obtenção dos dados. Teve como objetivo geral identificar as estruturas físicas recentes do atletismo brasileiro, seus objetivos e a distribuição geográfica das principais entidades promotoras deste esporte entre os anos de 2013 e 2016. Informações documentais foram obtidas por meio de sites esportivos, governamentais. Conjuntamente, realizou-se um levantamento de dados no site da Confederação Brasileira de Atletismo (CBAt) do ranking dos melhores atletas entre os anos de 2013 à 2016. A análise qualitativa foi realizada a partir dos preceitos do método Análise do Conteúdo de Bardin e a quantitativa, através do programa IBM SPSS Statistics para Mac, versão 20.0. Fizeram parte deste levantamento, no período supracitado, 4203 atletas de atletismo e suas respectivas instituições. Os resultados apontaram que há uma concentração maior das estruturas físicas esportivas destinadas tanto à iniciação esportiva, quanto ao rendimento, nas regiões de maior desenvolvimento econômico do pais (Sul e Sudeste), mas sem deixar de ter uma distribuição geográfica interessante, em algumas cidades das regiões Norte, Nordeste e Centro-Oeste. Destaca-se que há iniciativas por meio de construção, reformas e equipagem das instalações de atletismo. Constatou-se que a estrutura física desta modalidade em universidades públicas, clubes, instalações militares, complexos multiesportivos, instalações municipais, estaduais, federais, Centros Nacionais, Regionais e Locais. Porém, poucas delas oferecem equipamentos esportivos para o rendimento esportivo. Em suma, os achados deste estudo auxiliam o Brasil a melhor definir os objetivos para com o atletismo brasileiro.

PalavRAS-Chave: Atletismo; Estrutura física; Instituições esportivas; Instalações esportivas.

\section{Introdução}

Para que resultados expressivos sejam concretizados, uma série de fatores e medidas precisam ser levados em consideraçáo. Segundo ReEs et al. ${ }^{1}$, a partir da perspectiva do atleta de alto rendimento, levam em conta diversos fatores: data de nascimento, genética, fatores antropométricos e fisiológicos, locais de nascimento e de formação esportiva, programas de suporte aos atletas e, por fim, especialização precoce.

Nesse sentido, a promoção, a formação esportiva de atletas e a detecção de talento esportivo são uns dos fatores dentro de uma organização esportiva, fundamentais para entender o desenvolvimento do esporte de alto rendimento de um país ${ }^{2-5}$ ou, ainda, de uma modalidade ${ }^{6-8}$. Além das variáveis de desenvolvimento esportivo específicas dos atletas, a formação e a qualidade dos treinadores são aspectos fundamentais para um esporte obter excelentes resultados 9

Em uma perspectiva de âmbito nacional, Houlihan e GreEN ${ }^{10}$ ao analisarem a organizaçáo do sistema esportivo de alto rendimento de países, como, Canadá, Austrália e Reino Unido, encontraram quatro fatores comuns para o sucesso internacional no esporte e que, segundo os autores, 
merecem ser desenvolvidos por sistemas esportivos nacionais ou por determinadas entidades esportivas. São eles: instalaçóes de treinamento, estrutura física de qualidade; um total apoio para atletas; um conjunto de pessoal de apoio especializado para o trabalho do treinador; e integração entre programas de preparação para o treinamento e competição. Ainda, os autores salientam que cada naçáo possui uma característica, uma cultura própria, portanto, açôes organizacionais do esporte semelhantes, podem trazer resultados diferentes para cada contexto.

No estudo de, De Bosscher et al. ${ }^{11}$, juntamente com a organização internacional SPLISS (Sports Policy Factors Leading to International Sporting Success), apresentam um modelo teórico composto por nove pilares para a análise geral do esporte de um determinado país, a saber: 1) suporte financeiro; 2) organização e estrutura de políticas públicas para o esporte; 3) participação e esporte de base; 4) identificação de talentos e sistema de desenvolvimento; 5) suporte para atletas e póscarreira; 6) instalaçôes esportivas; 7) desenvolvimento e suporte para técnicos; 8) competiçôes nacionais e internacionais; e 9) pesquisa científica.

Apesar de existirem vários fatores fundamentais para o desenvolvimento do esporte, conforme apontado nesta introdução, o foco do presente estudo será na estrutura física da modalidade de atletismo no Brasil. Mais especificamente - com base na literatura ${ }^{1-6,10-11}-$, nos centros esportivos; na localizaçáo das principais equipes que desenvolvem o atletismo no Brasil; e nos objetivos (formação ou alto rendimento) para com o esporte pesquisado. $\mathrm{O}$ sucesso de uma determinada modalidade esportiva em um país pode ocorrer a partir do momento que os praticantes se desenvolvam em estruturas físicas e equipamentos similares a de competiçôes internacionais ${ }^{11-13}$. Os equipamentos esportivos são componentes das estruturas físicas e a insuficiência nesse aspecto, pode direcionar os objetivos e determinar os resultados ${ }^{4-11,14}$.

Sobre a estrutura física para o atletismo no Brasil, DigeL $^{5}$ salienta que, a partir de 1987 , a Confederação Brasileira de Atletismo (CBAt) tem mobilizado sua gestão para criação de um catálogo de possíveis novas pistas (com piso sintético) e outras estruturas esportivas para o atletismo. A International Association of Athletics Federations (IAAF) disponibiliza no seu site uma lista das pistas pelo mundo com certificação internacional, ou seja, pistas Classes 1 e $2^{\mathrm{a}}$ preparadas para competiçóes internacionais e, segundo esta entidade, o Brasil possui 8 pistas, são elas: Complexo de Atletismo Professor Oswaldo Terra da Silva (SP), Centro de Treinamento da Universidade Federal de Minas Gerais - UFMG (MG), Pista de Atletismo Ádria Santos (MG), Estádio Ícaro de Castro Mello (SP), Centro Olímpico de Treinamento e Pesquisa - COTP (SP), Estádio Olímpico João Havelange (RJ), Centro Nacional de Iniciaçáo e Excelência no Esporte (RJ) e Centro de Treinamento Paralímpico Brasileiro (SP) ${ }^{15}$.

Ainda, sabe-se que o atletismo é um dos esportes que mais renderam medalhas ao Brasil internacionalmente ${ }^{16}$. Segundo a CBAt - organização atual responsável pelas 27 federações estaduais - o país possui ótimos resultados no seu continente, uma vez que não é superado no Campeonato Sul Americano desde $1974^{16}$. No entanto, nos três últimos mundiais (2013, 2015 e 2017) da modalidade, o Brasil obteve somente duas medalhas: na prova de salto com vara e na marcha atlética ${ }^{16}$. Portanto, pode-se dizer que o país náo vêm obtendo resultados expressivos nas principais competiçôes internacionais de atletismo.

Dos 67 atletas que fizeram parte da equipe brasileira de atletismo nos Jogos Olímpicos do Rio, 46 $(68.65 \%)$ não passaram da primeira fase (qualificação para semifinal) em suas provas, sendo que das 47 provas (masculino e feminino) disputadas nos Jogos do Rio, o Brasil esteve entre os oito melhores em 6 (12.77\%) delas (salto com vara masculino, $20 \mathrm{~km}$ marcha atlética masculino, $20 \mathrm{~km}$ marcha atlética feminino, arremesso do peso, revezamentos 4x100 e $4 \times 400$ masculino $)^{17}$.

Com início do Ciclo Olímpico Rio 2016, percebeu-se no Brasil maior apoio, projetos, incentivos e visibilidade aos aspectos relacionados ao rendimento esportivo. Com base em alguns estudos relacionados com o esporte de rendimento de diversos locais do planeta, como no Brasil ${ }^{13-18}$, China $^{19}$, Inglaterra ${ }^{12}$, Canadá ${ }^{4}$, Austrália $^{20}$, uma nação desenvolvida esportivamente possui uma estrutura física esportiva seriamente definida e frequentemente voltada às modalidades que mais se destacam. Com a intençáo de aumentar a estrutura física de vários esportes no Brasil, criou-se sobretudo via Ministério do Esporte (ME), a Rede Nacional de Treinamento (RNT). O primeiro esporte beneficiado a fazer parte dessa rede é o atletismo ${ }^{21}$.

Contudo, esses são alguns argumentos apresentados, que servem para delimitar o seguinte questionamento para esse estudo: como se encontra atualmente a estrutura física do atletismo competitivo brasileiro? A partir disso, o objetivo do presente estudo é identificar as estruturas físicas recentes do 
atletismo brasileiro, seus objetivos e a distribuição geográfica das principais entidades promotoras deste esporte entre os anos de 2013 à 2016. Além disso, os objetivos específicos do trabalho são: a) verificar se estruturas físicas identificadas possuem equipamentos

\section{Método}

O presente estudo caracteriza-se, quanto aos fins, como de caráter quanti-qualitativo e, quanto aos meios, utiliza-se de pesquisa documental e bibliográfica ${ }^{22}$.

\section{Amostra}

Foi realizado um levantamento de dados no site da $\mathrm{CBAt}^{23}$, do ranking de todas as categorias existentes: Sub-16, Sub-18, Sub-20, Sub-23, Adulto e Corridas de Rua, bem como, as respectivas provas do atletismo entre os anos de 2013 à 2016. Optou-se, para esse estudo, em fazer análises separadamente por somente algumas destas categorias (Sub-16, Sub-18 e Adulto) e das seguintes variáveis disponibilizadas pelo site da CBAt: ranking dos 20 melhores atletas de cada prova, instituição que o atleta representa e a unidade federativa da instituição. Fizeram parte deste levantamento, no período supracitado, 4203 atletas de atletismo. Ainda, a partir do atleta, foi identificado a presença de 325 entidades que participaram do ranking da CBAt, no período supracitado.

\section{Documentos}

As informaçōes documentais relativas as estruturas das instituiçôes de atletismo; das instalaçôes esportivas e equipamentos esportivos destas instalaçóes, foram obtidas, principalmente, por meio de sites de órgãos governamentais (exemplo: Ministério do Esporte; Secretaria Nacional de Esporte de Alto Rendimento (SNEAR), Portal Brasil - Esporte, Portal da Transparência), de entidades esportivas (Comitê Olímpico Brasileiro, CBAt, federações estaduais, Federação Internacional de Atletismo - IAAF) e demais fontes de livre acesso adequadas ao objetivo deste estudo.

Conforme $\mathrm{GIL}^{22}$, a pesquisa documental vale-se de materiais que ainda não receberam uma interpretação, de acordo com os objetivos da pesquisa. Com base no autor, as fontes de papel - muitas vezes - são capazes de proporcionar ao pesquisador dados ricos para evitar a perda de tempo com levantamentos de campo. esportivos para o desenvolvimento do atletismo, na formação esportiva ou no alto rendimento; b) discutir o papel das estruturas físicas e das instituiçóes esportivas na construçâo do caminho do atleta, da formação ao alto rendimento.

Foram analisados um total de 18 documentos, referentes às instituiçôes e instalaçốes atuais de atletismo, não havendo, primeiramente, a definição de um recorte temporal. Destaca-se que, a instalaçáo mais antiga identificada neste estudo - no que se refere à manutenção da instalaçáo -, foi reformada em 2004. Ainda, serão detalhadas e discutidas algumas das açóes de desenvolvimento do atletismo no país, por exemplo: a Rede Nacional de Treinamento.

\section{Procedimentos}

Foi realizado num primeiro momento, um levantamento das instituiçóes de atletismo com maior número de resultados presentes no ranking da CBAt dos anos de 2013, 2014, 2015 e 2016. Em um segundo momento, foi realizado uma busca documental nos locais já mencionados acima com a intenção de identificar os Centros de Treinamento, pistas e instituiçóes referentes ao atletismo do Brasil. Embora entende-se que esta busca é parcial, uma vez que a informação relativa a muitos espaços de treinos não encontram-se disponíveis em documentos. Conjuntamente foi verificado se as instituições de atletismo identificadas pela busca documental receberam incentivos referentes à equipamentos esportivos.

Torna-se importante ressaltar a dificuldade metodológica deste tipo de estudo, pois algumas das variáveis utilizadas neste estudo estavam incompletas no site da CBAt, por exemplo, muitas instituiçóes possuíam somente siglas e não estavam com seus nomes completos. $\mathrm{O}$ ranking da $\mathrm{CBAt}$ não forneceu as cidades das entidades e foram identificadas pelos autores em sites de federaçóes estaduais de atletismo e em último caso buscou-se as informaçóes a partir do nome do atleta na web. Esse esforço geral na busca de informações foi fundamental para esta pesquisa no sentido de mapear corretamente as melhores equipes de atletismo do Brasil.

A importância do método de análise apresentado neste estudo, é que torna-se possível saber - efetivamente 
- quais instituiçóes (entende-se que também utilizam determinadas estruturas físicas) são consistentes e estão entre as melhores no cenário esportivo nacional. Pois, o que se encontra nos documentos nem sempre condiz com a realidade ou com os resultados das principais competiçóes nacionais.

\section{Análise dos dados}

Com as informações das variáveis descritas acima e com o auxílio do programa IBM SPSS Statistics para Mac, versão 20.0, foi possível cruzar tais variáveis, gerar alguns gráficos e tabelas apresentados nos resultados do estudo. Foi realizada uma análise separada por categorias (melhores instituições no Sub-16, Sub-18, Adulto e Corrida de Rua) e, posteriormente, realizada um diagnóstico geral envolvendo todas as categorias presentes no ranking da CBAt.

\section{Resultados}

Principais instituiçóes de atletismo no Brasil a partir do ranking da CBAt, entre os anos de 2013 à 2016: da formaçáo ao rendimento

Foi realizado um levantamento de dados no site da CBAt dos rankings dos anos de 2013 à 2016, dos resultados de atletas de diferentes categorias. A intenção é, descritivamente, apontar quais as instituições competitivas do país no atletismo obtiveram mais e melhores resultados neste período; bem como, identificar o nome completo e a localização destas equipes.

A quantidade de resultados (1306) dos atletas na FIGURA 1 é originada a partir das 20 equipes do país que obtiveram mais resultados no ranking nacional da categoria sub-16. A equipe que mais obteve resultados nesta categoria, foi a Associação Desportiva Centro Olímpico (Centro Olímpico) da cidade de São Paulo, a qual mantém seus treinamentos a partir da parceria com a prefeitura municipal, com 149 resultados (11,4\% do total de resultados das 20 equipes). $\mathrm{Na}$ sequência - com uma diferença considerável com relação ao Centro Olímpico - aparecem, respectivamente, as equipes: Associaçáo Sorriso de Atletismo (ASA) da cidade de Sorriso (MT), com 89 resultados; e Grêmio Recreativo Barueri (SP), com 85 resultados.

É importante destacar que São Paulo, com 7 equipes, é o estado com maior número de entidades
Então, a análise, criação dos gráficos e tabelas foram pensadas a partir das seguintes etapas: instituiçóes com maior número de atletas no ranking separadas por categorias; instituiçóes com maior número de atletas no ranking entre todas as categorias analisadas e por ambos os sexos, ponderando a colocação de cada atleta (finalidade qualitativa, foram criadas zonas de ponderação, valorizando os atletas mais bem colocados $-1^{\circ}$ ao $4^{\circ}$ receberam o valor de 200 pontos; do $5^{\circ}$ ao $8^{\circ}, 160$ pontos; do $9^{\circ}$ ao 12,120 pontos, isso sucessivamente até atingirmos a faixa que compreende do $17^{\circ}$ ao $20^{\circ}$, que receberam a valor de 40 pontos); instituiçóes por cidade e estado; categorias trabalhadas pelas melhores instituiçóes; e a quantidade de atletas por categoria. Também, foram elaborados quadros, identificando as instituiçôes encontradas a partir da busca documental e seus objetivos para com o esporte pesquisado.

entre as 20 que possuem mais resultados e totaliza assim, 683 resultados (52.29\%). A equipe com mais resultados (Centro Olímpico) é deste estado e compóem o ranking as seguintes equipes paulistas: Grêmio Barueri; Organizaçáo Funilense de Atletismo (ORCAMPI) de Campinas; Instituto Elizângela Maria Adriano (IEMA) da cidade de São Caetano do Sul; Associação dos Servidores Públicos Municipais de Pindamonhangaba; Serviço Social da Indústria (SESI) da cidade de Bauru; e Associação Sertanezina de Atletismo (ASA) da cidade de Sertãozinho.

Pode-se notar que o estado do Paraná esteve bem representado no ranking, tendo 5 equipes entre as 20 melhores: Associação de Atletismo de Maringá; Associação dos Servidores Municipais de Paranavaí (Asempar); Fundação de Esportes de Campo Mourão (FECAM); Curitiba - Secretaria Municipal de Esporte Lazer e Juventude (SMELJ); e Londrina Caixa Instituto Paranaense de Esporte e Cultura de Atletismo, totalizando 317 resultados (24.27\%) para este estado.

O estado do Rio de Janeiro, possui três equipes entre as 20: Brasil Foods/ILF-BRF - Instituto Lançar-se para o Futuro - RJ; Clube de Atletismo da Escola Municipal Francisco Caldeira de Alvarenga (EMFCA); e Clube de Regatas Vasco da Gama, todas da cidade de Rio de Janeiro, com um total de 178 resultados (13.26\%). Os estados de Santa Catarina, Minas Gerais, Pernambuco, Mato Grosso e Rio Grande do Sul, possuem uma equipe cada, respectivamente: Associação Corville de 
Atletismo de Joinville; Clã Delfos da cidade de Betim/ MG; Associação Atlética Santos Dumont (AASD) da cidade de Recife; e Prefeitura Municipal de Ivoti da cidade de Ivoti/RS.

Cabe destacar, também, o caso do SESI, instituição presente em diversas cidades e regióes do país. Como mencionado, optou-se - neste estudo - em especificar a localização das equipes. Ao analisar os resultados do SESI - mas sem diferenciar a cidade (no caso, cidades de Bauru, Osasco/SP, Uberlândia/MG e Natal) -, esta equipe obteve 86 resultados nesta categoria, ficando em terceiro lugar no número de resultados. Esse procedimento (de separar o SESI por cidade) também aconteceu nas demais categorias.

Essas 20 importantes equipes da categoria Sub-18 obtiveram um total de 1706 resultados. Conforme a FIGURA 2, os três clubes desta categoria que mais possuem resultados são do estado de São Paulo: Organização Funilense de Atletismo (ORCAMPI) de Campinas, com 179 resultados (10.49\%); IEMA de São Caetano do Sul, com 147 resultados (8.61\%) e Centro Olímpico da cidade de São Paulo, com 130 resultados (7.62\%). Além destas, o estado de São Paulo possui outras cinco equipes entre as $20 \mathrm{com}$ mais resultados no ranking da CBAt, a saber: Grêmio Recreativo Barueri; ASA da cidade de Sertãozinho; Fundação de Ciência, Tecnologia e Ensino (FUNDACTE) da cidade de Presidente Prudente; CSS II Exército da cidade de Osasco; e Serviço Social da Indústria (SESI) da cidade de Bauru - o que totaliza 48.1\% dos resultados das 20 equipes para o estado de São Paulo.

O estado de Santa Catarina, possui destaque nessa categoria, pois, 4 equipes são catarinenses: Uniâo Catarinense de Atletismo (UCA) da cidade de São José; Corville de Joinville; Associação Atletismo de Maringá e Associação Comunidade de Atletismo (ACA) da cidade de Itajaí, totalizando $16.82 \%$ dos resultados para este estado. Os estados do Rio de Janeiro e Paraná possuem 3 equipes cada: Brasil Foods, Vasco da Gama e EMFCA, todas da cidade do Rio de Janeiro; e FECAM de Campo Mourão, Londrina e Maringá. Os estados de Rio Grande do Sul e Minas Gerais, com uma equipe cada, respectivamente: SOGIPA de Porto Alegre e CRIA LAVRAS da cidade de Lavras.

Essas 20 principais equipes da categoria Adulto, obtiveram um total de 3267 resultados. Conforme a FIGURA 3, os quatro clubes desta categoria que mais possuem resultados no ranking da CBAt, entre os anos de 2013 à 2016, são do estado de São Paulo: Esporte Clube Pinheiros com 638 resultados (19.52\%); Clube

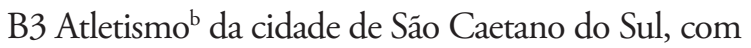
483 resultados (14.78\%); Organização Funilense de Atletismo (ORCAMPI) de Campinas, com 446 resultados (13.65\%); e ASA de São Bernardo do Campo, com 220 resultados (6.73\%).

As seguintes equipes também são paulistas: Grêmio Barueri; ASSEM da cidade de São José dos Campos; Luasa Sposts Caixa Taubaté (LUASA) da cidade de Taubaté; FUNDACTE de Presidente Prudente; ASA de Sertãozinho; Associação Comunidade do Atletismo (ACA) de São José dos Campos; Esporte Clube Rezende de Piracicaba; e Instituto Elizângela Maria Adriano (IEMA) da cidade de Sáo Caetano do Sul. Entre todas as categorias aqui analisadas, a Adulto é a que mais possui equipes do estado de São Paulo, são 12, responsáveis por $76.87 \%$ dos resultados das 20 equipes desta categoria.

$\mathrm{O}$ estado do Rio de Janeiro é o segundo com mais equipes, sendo representado por três equipes: Vasco da Gama, Brasil Foods, ambas da cidade do Rio de Janeiro e Associação Atlética Pé de Vento localizada na cidade de Petrópolis, assim este estado concentra 9.94\% dos resultados das 20 equipes. Os estados de Santa Catarina, Rio Grande do Sul, Minas Gerais, Paraná e Distrito Federal, com uma equipe cada - entre as 20 que obtiveram maior número de resultados -, respectivamente: Blumenau; Cruzeiro Esporte Clube (Belo Horizonte); SOGIPA de Porto Alegre; FECAM; Centro de Atletismo de Sobradinho (CASO) da cidade de Sobradinho (DF).

É importante destacar o surgimento de algumas equipes somente na categoria Adulto, entre as $20 \mathrm{com}$ mais resultados, tais como, Cruzeiro, CASO, Pé de Vento, São José dos Campos, Rezende e destaque para a equipe da B3 Atletismo, sendo a segunda colocada em número de resultados - entre os anos de 2013 e 2016.

Nota-se que as equipes Brasil Foods/ILF (RJ) e Orcampi, são as únicas que permanecem no campo nacional do atletismo, entre as 20 com maior número de resultados nas 3 categorias até aqui analisadas. Também, as equipes do Centro Olímpico (SP) e Corville (SC) aparecem entre as 10 melhores nas categorias sub-16 e sub-20, sendo que na Adulto, tais equipes nem figuram entre as 20 elencadas. Essa questão pode ser melhor detalhada, mais abaixo, na TABELA 2 .

Conforme a FIGURA 3, a equipe B3 Atletismo éuma das principais do cenário nacional de alto rendimento. Constatou-se que seu centro de treinamento indoor recebeu, em 2013, incentivos da CBAt - estes, oriundos do Comitê Olímpico Brasileiro (COB), para aquisição de equipamentos esportivos da prova salto com vara, uma vez que esta equipe (na ocasião) tinha uma forte equipe desta prova ${ }^{24}$. Na TABELA 1, é realizada uma análise geral das 20 equipes que mais obtiveram resultados envolvendo todas as categorias. 
FIGURA 1 - 20 instituições de atletismo do Brasil com mais resultados: 2013-2016 (categoria Sub-16).

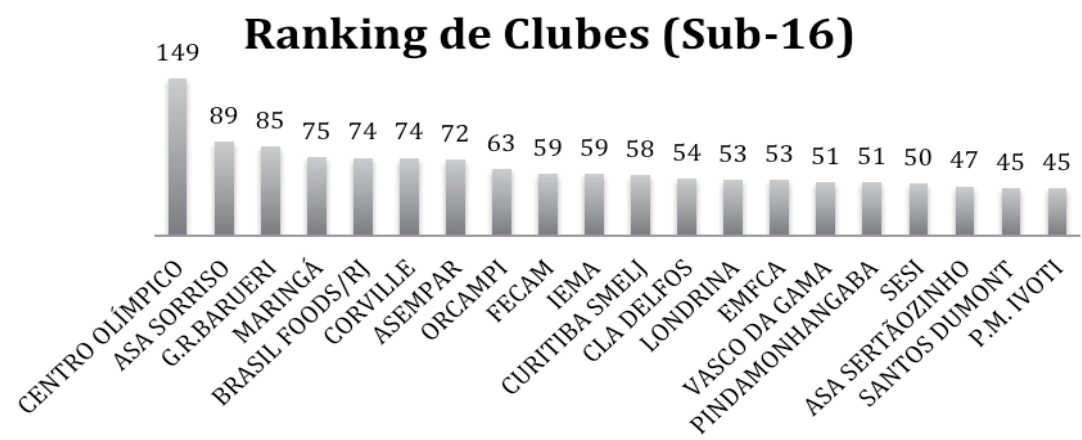

FIGURA 2 - 20 instituições de atletismo do Brasil com mais resultados: 2013-2016 (categoria sub-20).

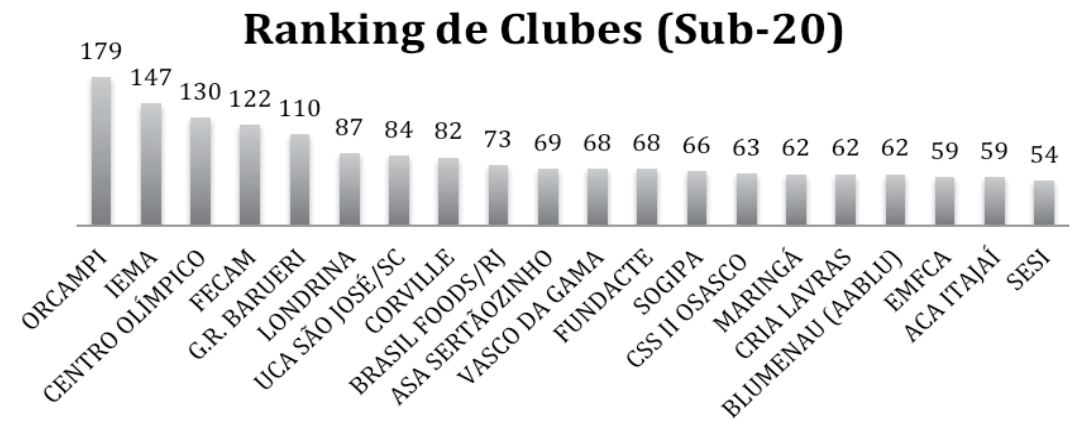

FIGURA 3 - 20 instituições de atletismo do Brasil com mais resultados: 2013-2016 (categoria Adulto).

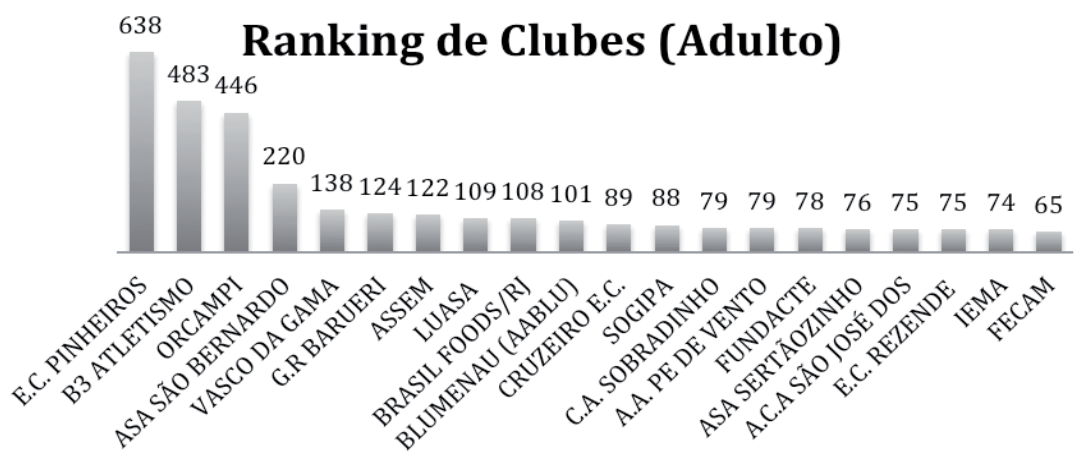


TABELA 1 - Principais instituições de atletismo do Brasil entre todas as categorias com base no número e na qualidade dos resultados obtidos (2013-2016).

\begin{tabular}{|c|c|c|c|c|c|}
\hline Quantitativo & Resultados & Qualitativo & Pontos & Var.* & \multirow{21}{*}{$\begin{array}{l}\text { Nota: Siglas destas } \\
\text { instituiçôes foram } \\
\text { detalhadas no decorrer } \\
\text { do texto. }\end{array}$} \\
\hline ORCAMPI & 1118 & ORCAMPI & 157.640 & -0 & \\
\hline E.C. PINHEIROS & 904 & E.C. PINHEIROS & 141.880 & -0 & \\
\hline CENTRO OLÍMPICO & 645 & B3 ATLETISMO & 96.360 & $\Delta_{1}$ & \\
\hline B3 ATLETISMO & 563 & CENTRO OLÍMPICO & 88.760 & $\nabla_{1}$ & \\
\hline GRÊMIO BARUERI & 537 & BRASIL FOODS & 71.280 & $\Delta_{2}$ & \\
\hline IEMA & 509 & IEMA & 64.840 & -0 & \\
\hline BRASIL FOODS & 492 & GRÊMIO BARUERI & 63.320 & $\nabla_{2}$ & \\
\hline FECAM & 477 & FECAM & 58.720 & -0 & \\
\hline ASA/SĀO BERNARDO & 443 & ASA/SĀO BERNARDO & 55.160 & -0 & \\
\hline CORVILLE & 433 & CORVILLE & 49.800 & -0 & \\
\hline VASCO DA GAMA & 407 & SOGIPA & 45.560 & $\Delta 4$ & \\
\hline ASA - SERTÃOZINHO & 384 & LONDRINA & 44.160 & $\Delta \mathbf{A}_{1}$ & \\
\hline LONDRINA & 381 & VASCO DA GAMA & 43.480 & $\nabla_{2}$ & \\
\hline CSS II EX. OSASCO & 351 & BLUMENAU (AABLU) & 42.280 & $\Delta_{2}$ & \\
\hline SOGIPA & 342 & ASA - SERTĀOZINHO & 42.000 & $\nabla_{3}$ & \\
\hline BLUMENAU (AABLU) & 323 & CSS II EX. OSASCO & 41.440 & $\nabla_{2}$ & \\
\hline ASSEM & 306 & FUNDACTE & 39.600 & $\Delta \mathbf{A}_{1}$ & \\
\hline FUNDACTE & 303 & ASSEM & 37.720 & $\nabla_{1}$ & \\
\hline A.A. MARINGÁ & 279 & ASA - SORRISO & 36.680 & $\Delta_{1}$ & \\
\hline ASA - SORRISO & 273 & A.A. MARINGÁ & 31.720 & $\nabla_{1}$ & \\
\hline
\end{tabular}

Conforme mencionado na metodologia deste estudo, foi dado um valor para a colocação de cada atleta no ranking da CBAt (zonas de ponderação). Na TABELA 1, existe uma análise por meio de uma abordagem, a qual definiu-se como quantitativa: instituiçóes com maior número de resultados no ranking, por ambos os sexos. Por outro lado, também revela as instituiçóes que possuem melhores resultados nas provas (abordagem qualitativa), ou seja, não basta apenas estar entre os 20 melhores do ranking (a CBAt fornece o ranking anual, por categoria, dos 20 melhores atletas por prova).

Comparando as duas abordagens, conclui-se que podem acontecer variações entre às instituiçốes. No entanto, boa parte das equipes sofreram pequenas mudanças, sendo o número 1 , a variação que mais se repetiu na tabela, isto é, equipes perderam uma posição (Centro Olímpico, ASSEM, Maringá); ou ganharam uma posição (B3 Atletismo, Londrina, FUNDACTE e ASA Sorriso), qualitativamente. O maior salto na tabela - em termos de qualidade de resultados - foi com a equipe da SOGIPA, a qual melhorou quatro posições na tabela $\left(15^{\circ}\right.$ posiçáo em número de resultados e $11^{\circ}$ em qualidade de resultados). Nesse sentido, justifica-se a importância da análise entre quantitativo e qualitativo, uma vez que nem sempre as equipes que possuem maior quantidade de resultados, possuem maior qualidade deles. A queda mais profunda no ranking qualitativo ocorreu com a equipe ASA Sertãozinho, caindo três posiçôes. A característica se mantém sem variação em cinco instituiçóes, destaque para as duas primeiras instituiçôes: Orcampi e Clube Pinheiros. A partir de uma análise envolvendo todas as categorias presentes no ranking da CBAt, observou-se que há instituiçóes no Brasil que apresentam resultados em mais de uma categoria, conforme revela a TABELA 2. 
TABELA 2 - 20 principais instituições de atletismo do Brasil entre todas as categorias com base no número e na qualidade dos resultados obtidos (2013-2016).

Nota. Siglas destas instituições foram detalhadas no decorrer do texto.

\begin{tabular}{|c|c|c|c|c|c|c|c|c|c|c|c|}
\hline \multirow[t]{2}{*}{ Categoria } & \multicolumn{2}{|c|}{ Sub-16 } & \multicolumn{2}{|c|}{ Sub-18 } & \multicolumn{2}{|c|}{ Sub-20 } & \multicolumn{2}{|c|}{ Sub-23 } & \multicolumn{2}{|c|}{ Adulto } & \multirow[t]{2}{*}{ Total } \\
\hline & $\mathbf{F}$ & $\mathbf{M}$ & $\mathbf{F}$ & $\mathbf{M}$ & $\mathbf{F}$ & $\mathbf{M}$ & $\mathbf{F}$ & $\mathbf{M}$ & F & $\mathbf{M}$ & \\
\hline ORCAMPI & 28 & 35 & 32 & 64 & 70 & 109 & 124 & 212 & 174 & 272 & 1118 \\
\hline E.C. PINHEIROS & & & 6 & 8 & 15 & 33 & 93 & 105 & 393 & 245 & 904 \\
\hline $\begin{array}{l}\text { CENTRO } \\
\text { OLÍMPICO }\end{array}$ & 83 & 66 & 105 & 94 & 67 & 63 & 68 & 35 & 38 & 24 & 645 \\
\hline B3 ATLETISMO & & 2 & 2 & & 3 & 2 & 31 & 29 & 254 & 229 & 563 \\
\hline GRÊMIO BARUERI & 53 & 32 & 46 & 65 & 53 & 57 & 68 & 34 & 59 & 65 & 537 \\
\hline IEMA & 17 & 42 & 41 & 73 & 80 & 67 & 65 & 51 & 39 & 35 & 509 \\
\hline BRASIL FOODS & 41 & 33 & 58 & 45 & 39 & 34 & 76 & 58 & 39 & 69 & 492 \\
\hline FECAM & 33 & 26 & 58 & 70 & 47 & 75 & 41 & 62 & 35 & 31 & 477 \\
\hline $\begin{array}{l}\text { ASA/SÃO } \\
\text { BERNARDO }\end{array}$ & 10 & 10 & 17 & 14 & 29 & 27 & 66 & 51 & 128 & 92 & 443 \\
\hline CORVILLE & 50 & 24 & 66 & 31 & 66 & 16 & 101 & 14 & 48 & 18 & 433 \\
\hline VASCO DA GAMA & 30 & 21 & 19 & 25 & 39 & 29 & 65 & 38 & 63 & 75 & 407 \\
\hline $\begin{array}{l}\text { ASA - } \\
\text { SERTÁOZINHO }\end{array}$ & 27 & 20 & 16 & 53 & 26 & 43 & 27 & 96 & 33 & 43 & 384 \\
\hline LONDRINA & 34 & 19 & 28 & 80 & 47 & 40 & 44 & 38 & 40 & 10 & 381 \\
\hline $\begin{array}{l}\text { CSS II EXER./ } \\
\text { OSASCO }\end{array}$ & 7 & 21 & 44 & 31 & 26 & 37 & 61 & 71 & 25 & 28 & 351 \\
\hline SOGIPA & 16 & 24 & 41 & 34 & 45 & 21 & 32 & 39 & 39 & 49 & 342 \\
\hline $\begin{array}{l}\text { BLUMENAU } \\
\text { (AABLU) }\end{array}$ & 11 & 21 & 26 & 33 & 25 & 37 & 35 & 34 & 54 & 47 & 323 \\
\hline ASSEM & 12 & 15 & 27 & 14 & 24 & 15 & 54 & 21 & 64 & 58 & 306 \\
\hline FUNDACTE & 11 & 6 & 9 & 45 & 13 & 55 & 13 & 73 & 15 & 60 & 303 \\
\hline A.A. MARINGÁ & 39 & 36 & 49 & 23 & 50 & 12 & 25 & 14 & 12 & 20 & 279 \\
\hline ASA SORRISO & 52 & 37 & 51 & 30 & 33 & 8 & 35 & 7 & 16 & 4 & 273 \\
\hline
\end{tabular}

É importante destacar que as principais equipes em número de resultados, se mantiveram competindo ao longo dos anos analisados. Observou-se que, das 20 equipes, somente o Clube Pinheiros e a B3 Atletismo não possuem resultados, ou pode-se dizer atletas, em todas as categorias e sexos. Identificou-se que $92,47 \%$ dos resultados do Pinheiros e $96.45 \%$ da B3 Atletismo, se concentram nas categorias Sub-23 e Adulto. Tal fato, de acordo com a TABELA 1 (análise entre quantidade e qualidade entre todas as categorias), faz dessa equipe uma das principais do país no atletismo. Contudo, a mesma foca seus esforços, quase que exclusivamente, em atletas que se encontram nos níveis intermediários e avançados de performance esportiva. Essa lógica também pode ser vista em outras equipes, como: Orcampi, ASA São Bernardo, Sertãozinho, Vasco da Gama, ASSEM e FUNDACTE. Muito embora, essas equipes possuam resultados nas categorias menores, mas, em menor proporção que nas categorias Sub-23 e Adulto. Por exemplo, as equipes do Vasco da Gama e da ASA São Bernardo, as quais não se encontram entre as 10 melhores nas categorias Sub-16 e Sub-18 - embora constata-se, na TABELA 2, que as mesmas possuem atletas competindo nessas categorias.

Por outro lado, identificou-se que algumas equipes, como Maringá (PR), ASA Sorriso (MT), Centro Olímpico de São Paulo, apresentam o processo inverso. A Tabela 2 revela, por exemplo, que esta última instituição tem uma queda considerável no número de resultados, a partir da categoria Sub-20. A média de resultados desta equipe por categoria é 129, sendo que na categoria adulta o Centro Olímpico possui somente 62 resultados $(9.61 \%)$, valor muito abaixo da média. Observou-se que essa equipe encontra-se entre as melhores do país nas categorias iniciais do atletismo, mas de fato, o mesmo não acontece na categoria Adulto. 
Apesar das equipes serem destaques ou na formação esportiva, ou no alto rendimento, torna-se possível afirmar que 18 das 20 equipes apresentadas, possuem o caminho completo, da descoberta do talento ao alto rendimento, pois fornecem oportunidade para seus atletas competirem desde as categorias iniciais até o alto rendimento. Outro ponto de destaque é que equipes supracitadas forneceram a maioria dos atletas que representaram o Brasil nos Jogos Olímpicos do Rio, por exemplo, dos 67 atletas participantes do atletismo no Rio, 16 (23.88\%) estavam vinculados à B3 Atletismo; 12 (17.91\%) ao Clube Pinheiros; e 6 (8.95\%) à Orcampi - como destaque da Orcampi, o campeão olímpico Thiago Braz da Silva (salto com vara).

A FIGURA 4, revela que o atletismo se faz presente em todas as regiôes do país. As cidades de Rio de Janeiro e São Paulo são as que mais possuem equipes competindo no ranking da CBAt, mas também foram observadas - neste ranking - instituições que desenvolvem a modalidade em cidades como Fortaleza, Natal (Regiāo Nordeste), Manaus, Belém (Região Norte), Brasília e Campo Grande (Centro-Oeste). Embora, conforme já evidenciado, pode-se afirmar que essas cidades não possuem instituições classificadas como as melhores do país.

O Estado de São Paulo é o primeiro colocado no número de instituiçóes (76), seguido - de longe - por Santa Catarina (23), Paraná (18), Rio de Janeiro (18) e Ceará (16). Os dez primeiros colocados no número de instituiçóes acabam por representar quatro regiōes brasileiras: Sudeste, Sul, Nordeste e Centro Oeste. Estados com baixa populaçáo e/ou baixo Produto Interno Bruto (PIB), aparecem mais atrás, como Sergipe, Tocantins, Alagoas e Roraima. Foi possível observar que os estados do Acre e Amapá não tiveram instituiçôes representadas no ranking da CBAt entre os anos de 2013 e 2016.

Quando compara-se as duas figuras (esquerda e direita), os estados que desenvolvem a base e o alto rendimento do atletismo nacional, existem poucas mudanças: no nível, alto rendimento - considerando aqui as categorias sub-23 e Adulto -, os estados do Mato Grosso (equipe: ASA Sorriso) e Pernambuco (Santos Dumont, Recife) já não estão presentes neste nível, entre as 20 instituiçóes com mais resultados no ranking da CBAt, e ainda, aparece o Distrito Federal (CASO Sobradinho). Os demais estados (RS, SC, PR, SP, RJ, $\mathrm{MG}$ ) permanecem entre os melhores desta análise, tanto nas categorias de base, quanto nas categorias do alto rendimento.

Em relação ao número de equipes, observa-se também, algumas mudancas, por exemplo: o estado do Paraná é o segundo colocado no número de equipes de base, com 6 , entre as 20 equipes que possuem mais resultados nas categorias de base (sub-16, sub-18 e sub-20), e no alto rendimento, possui duas equipes (FECAM e Londrina). Já estados como Sáo Paulo e Rio de Janeiro, foi possível notar um aumento da base para o alto rendimento, no que se refere ao número de equipes por estado.

\section{Identificando documentalmente outras estruturas para o treinamento de Atletismo}

A intenção deste tópico é revelar algumas estruturas físicas, ou locais no Brasil destinados ao desenvolvimento atletismo e não identificados na busca anterior, a partir do ranking da CBAt.

O CFT de Jacarepaguá poderá possuir parceria com o empreendimento da Fiocruz (Complexo da Fiocruz: possui pista de atletismo) e ser utilizado para o desenvolvimento do atletismo. Importante destacar que o Centro Olímpico da Barra, construído para os Jogos Olímpicos do Rio de Janeiro, não possui - até o momento da pesquisa (2018) - pista de atletismo. Já o Complexo de Deodoro, possui pista oficial de atletismo, obra construída em parceria entre a empresa Vale do Rio Doce, o Ministério do Esporte e o Exército ${ }^{25,26}$.

O atletismo dos Jogos Olímpicos do Rio de Janeiro foi realizado no estádio do Engenháo, o qual foi todo reformado, remodelado, incluindo uma pista de atletismo conexa com tal estádio, utilizada na ocasiáo dos Jogos para aquecimento dos atletas. Atualmente, o Engenhão é mantido por um clube de futebol, o Botafogo, isto é, atualmente pratica-se futebol na estrutura usada para realizar o atletismo nos Jogos Olímpicos do Rio.

Com relação aos equipamentos, materiais esportivos utilizados no atletismo dos Jogos do Rio, para aquecimento dos atletas e na realização das provas oficiais, poucas informaçóes documentais foram encontradas sobre essa questão. Sabe-se que tais materiais (exemplo: blocos de partidas, dardos, pesos, discos, etc.) foram alugados pelo Comitê Organizador dos Jogos, por meio da empresa chamada Mondo - a qual desenvolve e fabrica pisos indoor, outdoor e equipamentos esportivos ${ }^{27}$ - e, após o término dos Jogos, os materiais foram devolvidos a esta empresa. Então, pode-se dizer que não existiu um legado no sentido do país reaproveitar e distribuir todos os materiais esportivos, utilizados para o atletismo nos jogos do Rio, nas suas diversas estruturas físicas que foram implementadas. 
FIGURA 4 - Cidades com 4 ou mais entidades: 2013-2016 (todas as categorias).

\section{Instituições por cidade}

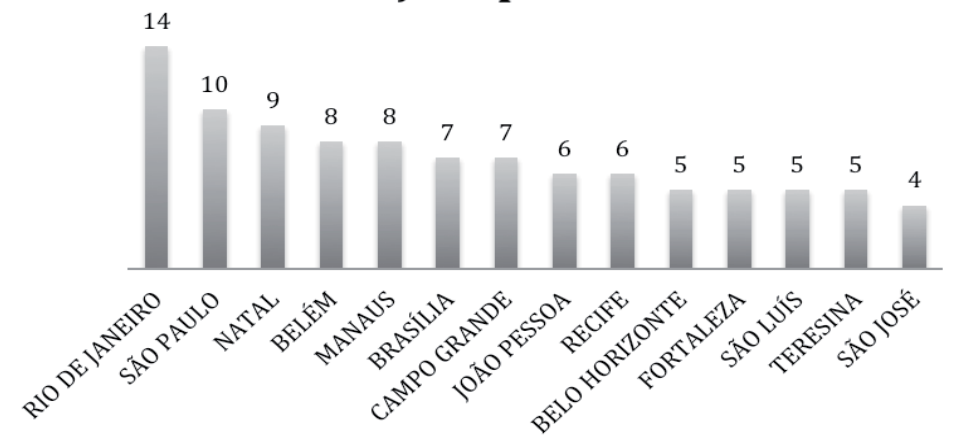

FIGURA 5 - Mapa Brasil.

Esquerda: distribuição das 20 instituições do atletismo nacional (2013 - 2016), com mais resultados (sub-16, sub18, sub-20). Direita: distribuição das 20 instituições do attetismo nacional (2013 - 2016), com mais resultados (sub-23, adulto).

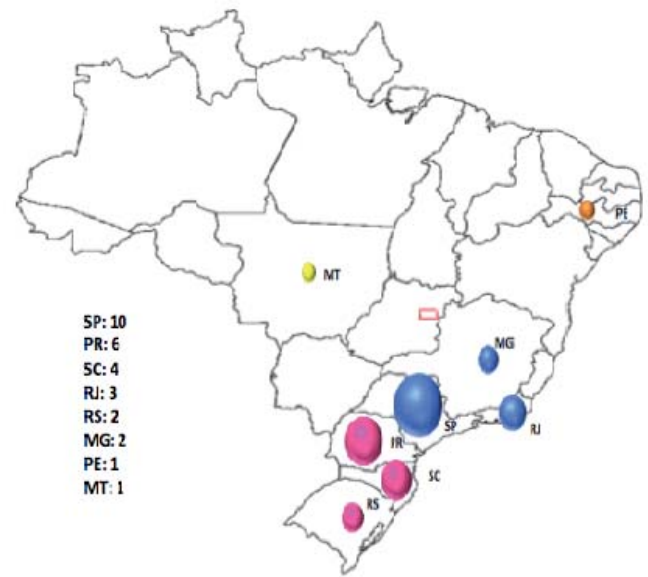

O Cento de Treintamento (CT) de Atletismo em Cascavel/PR foi lançado em 2014 e com término previsto para o final de 2016. Trata-se de um complexo esportivo de padrão internacional (IAAF) - com alojamentos, piscina, salas de musculação e de aula, arquibancada, auditório - que envolveu recursos do governo federal, em parceria com o governo do estado do Paraná, num total de R\$36 milhões ${ }^{28}$. Até o momento da pesquisa (2018), não foram identificadas informações precisas com relação aos objetivos desta estrutura para o atletismo nacional, tampouco se a obra foi concluída.

Em Itamonte/MG, previa-se a construção de duas pistas de atletismo envolvendo a parceria prefeitura, estado e Ministério do Esporte, de forma mais precisa: a partir desta parceria, seria implantado um centro de altitude no local, uma vez que a região de Itamonte

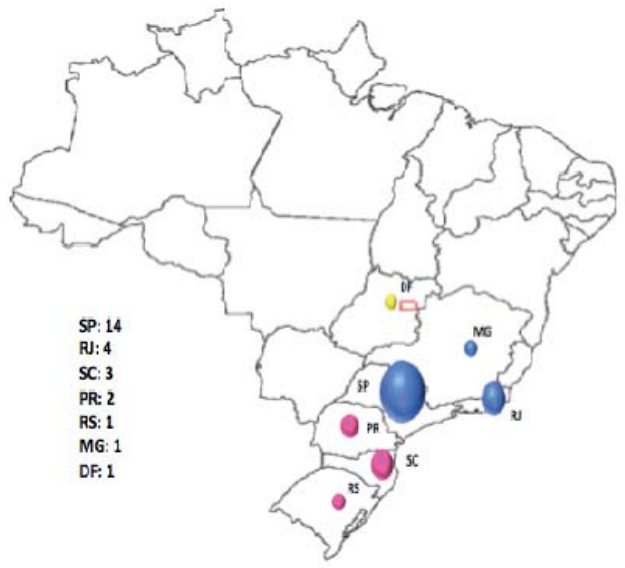

localiza-se a 2.400 metros do nível do mar, e assim, os atletas brasileiros não precisariam mais viajar para o exterior para melhorarem o condicionamento físico, gerando economia ${ }^{29}$.

Identificou-se que esse espaço, atualmente, é utilizado por uma das principais equipes de atletismo chamada "Pé de Vento" (ver FIGURA 3), especialista em provas de meio fundo e fundo. Em Itatiaia/RJ, Parque Nacional de Itatiaia, existe o planejamento de CT de Altitude na propriedade da Fundação Pró-Natura. A Academia Militar de Agulhas Negras (AMAN), em Resende/RJ, propriedade do Exército brasileiro e reformado para os Jogos Mundiais Militares de 2011 no Brasil, possui em funcionamento o Centro de Excelência em Aptidão e Reabilitação Física Capitão Cláudio Coutinho, local onde desenvolvem-se diversos trabalhos com atletas brasileiros do atletismo. Itamonte/ 
MG, Itatiaia/RJ e Resende (AMAN), por serem localidades próximas, formariam o Polo de Itamonte ${ }^{29}$, cujo foco principal seria o atletismo de alto rendimento das provas de meio fundo e fundo. Sob esse aspecto, foi encontrado - no site do Portal da Transparência - que o convênio para construçáo de tais pistas foi anulado ${ }^{30}$.

Um CT Paralímpico para 15 modalidades, incluindo o atletismo, está em funcionamento no estado de São Paulo, sendo construído com a parceria federal e Comitê Paraolímpico do Brasil. O da cidade de Recife possui uma pista Classe 2 e o foco principal é a formação de atletas. Foi construído pelo Estado de Pernambuco e recebeu incentivos do mesmo para reforma da pista de atletismo.

Também no estado de São Paulo, encontra-se o Estádio do Grupo Rede Energia, da extinta equipe conhecida como Rede Atletismo na cidade Bragança Paulista, com amplas instalaçóes que estão em fase final de construção, mas em funcionamento com pista Classe 2. Tal espaço, a partir de 2017, está sendo utilizado e administrado pela CBAt como a casa do atletismo brasileiro, sendo um centro nacional para receber atletas e treinadores de diversas categorias ${ }^{31}$.

O CETE (Centro Estadual de Treinamento Esportivo), em Porto Alegre/RS, mantido pelo governo do estado, teve - em outubro de 2013 - a reconstrução de sua pista de atletismo com auxílio do Ministério do Esporte e, também, recebeu equipamentos esportivos para o desenvolvimento de atletas da base, ao alto rendimento ${ }^{32}$. Em Brasília, existe o CIEF (Centro Interescolar de Educação Física), por sinal, esse é o primeiro projeto, cuja abordagem ocorre também em aulas curriculares de Educação Física e extracurriculares no ambiente escolar. O Estádio de Atletismo Célio de Barros no Rio de Janeiro, junto ao complexo do Maracanã, teve a recuperação da pista Classe 2 aprovada $^{33}$, mas - até o momento do término deste estudo (2018) não fora encontrada informação sobre a entrega da reforma, ou utilização atual deste espaço.

Algumas pistas, com classificação internacional, foram estruturadas a partir de um convênio ${ }^{c}$ de R\$ 13.032.000,00 milhōes (vigência, de 2011 a 2015), entre CBAt e Ministério do Esporte, a saber: UNIFOR, de Fortaleza; Pista de Atletismo Ádria Santos, do SESI (Serviço Social da Indústria), de Uberlândia; CEFAN (Centro de Educação Física Almirante Adalberto Nunes) e a UniFA (Universidade da Força Aérea), no Rio de Janeiro; Centro Olímpico de Treinamento e Pesquisa e o Complexo do Ibirapuera (Estádio Ícaro de Castro), ambos da Prefeitura da cidade de Sáo Paulo. Deste modo, esses complexos foram considerados pela CBAt, no período acima, como Centros Nacionais de Treinamento de Atletismo, visando preparaçáo para os Jogos Olímpicos do Rio. Assim, a verba supracitada também foi destinada a aquisição de diversos equipamentos esportivos utilizados nestes Centros, os quais, desenvolvem atualmente o atletismo competitive.

Vale destacar que, a UNIFA, com duas pistas de atletismo (uma reformada em 2011 e a outra, construída em 2016), foi a casa do atletismo brasileiro durante os Jogos Olímpicos do Rio de Janeiro e, a partir de 2017, tornou-se novamente um Centro Nacional do Atletismo, como parte integrante da Rede Nacional de Treinamento ${ }^{34}$. Entidades pontuais melhoraram suas condiçóes de treinamento de atletismo recentemente a partir de recursos oriundos do Ministério do Esporte, como o Esporte Clube Pinheiros, vinculado à estrutura física da CEPEUSP. Já o SESI de Blumenau/SC (possui pista Classe 2, mas precisou ser reformada devido as enchentes de 2008) e no SESI de Uberlândia/ MG, foi possível identificar que receberam recursos do Ministério do Esporte para compra de equipamentos esportivos ${ }^{35}$.

O clube SOGIPA (Sociedade de Ginástica de Porto Alegre), teve em 2012, um projeto aprovado em uma chamada pública da Secretaria Nacional do Esporte de Alto Rendimento (SNEAR), no valor total de R \$ 559.248,55 para aquisição de equipamentos esportivos para várias modalidades, entre elas, o atletismo ${ }^{34}$. Ainda, consta nesta chamada pública, que o Clube Pinheiros teve um projeto aprovado no valor de $\mathrm{R} \$ 5.693 .973,84$ para aquisição de equipamentos esportivos de 15 modalidades, entre elas, o atletismo ${ }^{35}$.

Foi possível identificar a construção de pistas oficiais de atletismo em diversas Universidades Federais: Rio Grande do Sul, Paraná, Santa Catarina, Minas Gerais, Lavras (MG), Juiz de Fora (MG), Goiás, Piauí, Espírito Santo, Tocantins (Campus Palmas), Rio Grande do Norte, Maranhão, Sergipe e Paraíba. Ainda em fase de construção, estáo as pistas das seguintes Universidades Federais: Alagoas, Ceará, Pernambuco, Mato Grosso, Tocantins (Campus Miracema), Vale do Jequitinhonha e Mucuri (MG) e Universidade de Brasília (UNB) 30-32-34.

Além disso, é importante destacar algumas parcerias, envolvendo o governo federal e prefeituras municipais, para construção de pistas oficiais de atletismo, como a da cidade de Jaraguá do Sul (SC), inaugurada em 2015. As pistas de atletismo vinculadas às prefeituras de: Campo Grande (MS), São Bernardo do Campo 
(SP), São Caetano do Sul (SP) e Boa Vista (RR), encontram-se - no momento da pesquisa (2018) em funcionamento ${ }^{30-34}$

No site Portal de Convênios - SICONV de é possível identificar um convênio ( $n^{\circ} 813.831 / 2014$ ) entre Ministério do Esporte e CBAt, com início da vigência em 2015, com o objetivo de auxiliar na criação da Rede Nacional de Treinamento (RNT) de Atletismo. O valor global do contrato é de R\$26.587.348,68, divididos entre 2015 e 2017. Destes, R $\$ 16.851 .747,00$ (63.38\%) foram empregados em 2015, ano que antecedeu os Jogos Olímpicos do Rio de Janeiro. Esse contrato prevê que tais valores podem ser aplicados em diversos aspectos relacionados a RNT, como, recursos humanos: gerentes dos centros, analistas de desempenho, psicólogos, fisioterapeutas, treinadores, atletas, etc., que faráo parte das estruturas físicas parceiras da RNT; e recursos materiais, como aquisição de equipamentos.

\section{Discussão}

A partir das estruturas físicas diagnosticadas, há tentativa de alinhamento para uma política nacional, voltada à formação de uma Rede Nacional de Treinamento da modalidade de atletismo, uma vez que foram identificados alguns centros locais, regionais e nacionais de treinamento e muitas estruturas físicas constituídas por meio de uma articulação envolvendo governo federal, estados, prefeituras e universidades. Alguns autores apontam que o esporte brasileiro, como um todo, ainda não possui na prática um sistema nacional de esporte, sendo que uma das finalidades seria, justamente, fornecer a ligação entre as estruturas dos municípios, estados e governo federal ${ }^{13-18-37}$.

Instituições esportivas, como - associações, institutos e prefeituras - constituem parte das entidades presentes no esporte competitivo do atletismo nacional, sobretudo, nas etapas mais formativas desta modalidade. A distribuição das 20 melhores equipes pelo país, encontra-se muito concentrada em poucos municípios e em determinadas unidades federativas, visto que $73 \%$ dos atletas pertencem ao estado de São Paulo. Em seguida, com percentagem bem inferiores, aparece o Rio de Janeiro e depois os estados da Região Sul, Paraná, Santa Catarina e Rio Grande do Sul. Destacase que as equipes apresentadas nos resultados - com base na análise do ranking da CBAt - estão presentes neste ranking em todos os anos do período analisado (2013-2016). São equipes consistentes, levando em
É possível identificar neste convênio, que o investimento será aplicado entre as principais estruturas (Centros de âmbito nacional) atuais que irão compor a RNT de Atletismo, a saber: 2 Centros Nacionais, com caráter de alto rendimento (Bragança Paulista e Rio de Janeiro: UNIFA); 2 Centros Regionais, com viés de desenvolvimento esportivo e início da especialização (Lavras/MG e Natal), com presença de atletas, técnicos; e outros 8 Centros Locais, com objetivo de atração de talentos. Os centros locais devem acontecer em Manaus, Porto Alegre (SOGIPA), Fortaleza (UNIFOR), Teresina (UFPI), Campinas (Orcampi), Sorriso (MT) - ASA Sorriso, Joinville (SC) - Corville e Campo Mourão (PR) - FECAM ${ }^{36}$. Ressalta-se que, estruturas tidas anteriormente (por exemplo, até 2015), como Centros Nacionais (Uberlândia, Manaus e Fortaleza), atualmente, tornaram-se dentro da Rede Nacional de Treinamento de Atletismo e sob a perspectiva da CBAt, como Centros Locais.

consideração as diversas categorias do atletismo e com tradição na modalidade.

A partir da identificação das estruturas físicas de atletismo e das equipes que representam o cenário competitivo no país, torna-se importante destacar a relação (ou não) do atletismo nacional com o esporte escolar. A FIGURA 1 (equipes das categorias de base do atletismo) revela que o sistema competitivo do atletismo nacional não está priorizando o esporte na escola para o desenvolvimento de jovens atletas, mas sim, em outras entidades, tais como, associaçóes, clubes e prefeituras. $\mathrm{O}$ atletismo é uma modalidade que pode, facilmente, ser ensinada na escola além das aulas curriculares de Educaçáo Física, pois espaço físico e materiais esportivos podem ser "adaptados" na sua iniciação esportiva ${ }^{38,39}$. Portanto, o conveniente seria aproximar o contexto escolar das estruturas físicas apontadas neste estudo, pois, conforme aponta GREEN ${ }^{12}$, uma boa estrutura física adequada contribui na formação de jovens atletas de um país.

Nesse estudo, constatou-se que a maioria dos clubes de atletismo do país, possui atletas em todas as categorias analisadas. No entanto, existem equipes que priorizam os níveis mais altos de rendimento, não dando atenção necessária às etapas mais formativas. Vários estudos concluíram que os resultados competitivos, não devem ser o principal parâmetro das instituiçóes que desenvolvem formação de jovens atletas de diferentes 
modalidades ${ }^{7-8,40,41}$. Brito, FonsECA, e Rolim ${ }^{40}$, em um estudo com atletas portugueses de atletismo, identificaram que obter excelentes resultados enquanto jovens não garante bons resultados, por exemplo, quando os mesmos atingirem a categoria Adulto. Similarmente, Hollings, Mallett e $\mathrm{Hume}^{7}$ e Huxlei, O'connor e Bennie ${ }^{8}$ identificaram que os atletas juniors que seguiram carreira no atletismo, obtiveram destaque internacional a partir de uma especialização tardia, quando atingiram a categoria adulto. Conforme Vasconcelos-Raposo et al. ${ }^{41}$, em outro estudo na modalidade de atletismo, identificaram que a mudança de instituição e, consequentemente, de ambiente, pode - muitas vezes - prejudicar a formação de jovens atletas, os levando ao abandono prematuro das competiçóes.

Assim, ressalta-se a importância de uma equipe de atletismo brasileira, de alto rendimento, também desenvolver as categorias iniciais da modalidade, o que facilitaria na organização e definição do caminho do atleta no atletismo. No futebol, alguns clubes brasileiros passaram - a partir de 2011 - a ser reconhecidos pela Confederação Brasileira de Futebol como Entidade Formadora de Atleta. Isso ajudou essas entidades a terem uma proteção na formação deles, como, sempre que ocorrer uma transferência nacional de atleta, até $5 \%$ do valor pago pelo novo clube serão distribuídos pelos clubes formadores ${ }^{42}$. O futebol no Brasil, por exemplo, por uma questáo cultural $^{37-43}$, consegue render quantias significantes aos cofres dos clubes ${ }^{43}$. A intenção aqui não é comparar valores dessas duas modalidades, mas colocar que o atletismo brasileiro também poderia valorizar, de alguma forma, seus clubes formadores. Não foi identificado, até o momento deste estudo (2018), se a CBAt oferece benefícios às entidades reveladoras de atletas para campeonatos internacionais ou que formaram medalhistas olímpicos.

É importante salientar que várias equipes destaques do atletismo nacional, identificadas por meio da análise do ranking da CBAt, não apareceram na busca documental. Por exemplo, as equipes ASA Sertãozinho; Grêmio Recreativo Barueri; Guarulhos; Rezende/Piracicaba; CASO de Sobradinho; entre outras. São equipes classificadas entre as melhores do país e não foi possível identificar de forma documental, uma estrutura física para o atletismo em cidades como: Barueri, Franca, Sobradinho, Paranavaí, Guarulhos e Piracicaba.

Então, a presente pesquisa revelou onde se localizam as principais estruturas físicas de atletismo do Brasil, tanto na formação, quanto no rendimento o que pode vir a contribuir para a elaboração de alguns critérios para a Rede Nacional de Treinamento (RNT) de atletismo. Segundo o Ministério do Esporte, a RNT tem por objetivo criar um caminho para o atleta, desde a descoberta do talento, garantindo a formação da base até a especialização no treinamento dos atletas das seleçóes nacionais, com toda a qualificaçáo que isso requer ${ }^{21}$. Para alguns autores, saber a localizaçáo dos principais centros esportivos que desenvolvem o esporte em diferentes níveis ${ }^{13,14-18}$, é um raciocínio que serve para saber aonde deve ser o investimento pontual.

Outro ponto relacionado com as estruturas físicas, é a questão dos equipamentos esportivos, destinados para determinadas espaços esportivos que contemplam o atletismo. Para De Bosscher et al. ${ }^{11}$ e FERreira ${ }^{18}$, as infraestruturas aliadas aos recursos materiais disponíveis (nesse caso, equipamentos esportivos), interferem no desenvolvimento do esporte de alto rendimento, auxiliando um país, na obtenção de excelentes resultados em competiçóes internacionais. Já os estudos de DiGEL ${ }^{3}$, FIN $^{44}$, JARVIER e SIKEs ${ }^{45}$ sobre o atletismo em alguns países africanos - como Quênia, Etiópia e Jamaica - apontam que a estrutura física não está entre os principais fatores para tais países serem, mundialmente, tradicionais neste esporte.

No tópico deste estudo (identificando estruturas físicas), ao identificar as estruturas físicas de atletismo, foi possível constatar que, algumas delas, receberam incentivo para a aquisição de equipamentos esportivos, como: SOGIPA, Esporte Clube Pinheiros, CETE, SESI Uberlândia e Blumenau, São Bernardo do Campo ${ }^{21-30}$.

No convênio já citado neste estudo, o qual trata especificamente da criação da Rede Nacional de Treinamento (RNT) de Atletismo (convênio no 813.831/2014 - SICONV), constatou-se que foi investido $\mathrm{R} \$ 1.723 .313,72$ em equipamentos esportivos para os Centros Nacionais, Regionais e Locais. Assim, pode-se dizer que, tais equipamentos, serão utilizados pelos centros que irão compor a RNT de Atletismo. O QUADRO 1, representa as estruturas físicas - diagnosticadas ao longo deste estudo - que receberam equipamentos esportivos para desenvolverem o atletismo em suas equipes.

Identificou-se, conforme QUADRO 1, que a equipe do Centro Olímpico da cidade de São Paulo recebeu investimentos para aquisição de equipamentos esportivos. Por outro lado, não foram encontradas informaçóes se a equipe da Orcampi recebeu recursos públicos para esse fim. 
QUADRO 1 - Estruturas físicas de atletismo que recentemente receberam novos equipamentos esportivos.

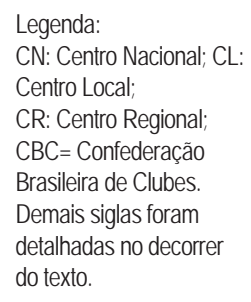

Pensando em efetividade na aplicação de recursos, seria o ideal tal instituição também possuir parceria, receber apoio, para os equipamentos esportivos de atletismo, uma vez que foi uma das melhores equipes de alto rendimento do país, entre 2013 e 2016. Já a equipe do Centro Olímpico, deve continuar recebendo recursos, mas que contemplem à iniciação esportiva e especializaçáo inicial, haja vista os dados revelarem que a mesma é formadora de atletas, não desenvolvendo com grande ênfase a modalidade em níveis mais elevados do alto rendimento. Isso seria somente um exemplo, que poderia ser aplicado para outras equipes do atletismo nacional.

Com base nas fontes apresentadas e da análise a partir do ranking da CBAt (20 equipes com mais resultado), foram diagnosticadas 79 estruturas físicas e o QUADRO 1 revela que 20 (25.31\%) receberam, investimentos públicos em equipamentos esportivos, destinados ao desenvolvimento do atletismo de rendimento. Sabe-se, conforme mencionado nos resultados, que algumas equipes do atletismo nacional são mantidas financeiramente, principalmente, por patrocínios privados, como os casos da Orcampi, e B3 Atletismo ${ }^{24}$. Porém, não foi possível identificar, confirmar, se as instituiçóes de atletismo receberam, financiamento privado para a compra de materiais esportivos.

Portanto, esse é um ponto dentro da Rede Nacional de Treinamento que merece discussão, pois náo basta para o país possuir estrutura física oficial excessiva para o atletismo, sem ter equipamentos esportivos adequados (qualidade e quantidade) para sua prática, sobretudo no espaço de rendimento desta modalidade. Segundo vários autores, as estruturas físicas conforme padróes internacionais são fundamentais no processo que visa o alto rendimento esportivo. Porém, sem as condiçóes ideais de treinamento e de utilização destas estruturas, as possibilidades de sucesso são prejudicadas e restritas, ou até improváveis ${ }^{18,44-46}$.

Ainda, foi identificada uma notícia no site do Ministério do Esporte (ME) indicando que foram investidos um total de $\mathrm{R} \$ 70$ milhões para construção de 15 novas pistas de atletismo, distribuídas em 11 estados brasileiros. 
QUADRO 2 - Objetivos das estruturas físicas para o atletismo brasileiro.

\begin{tabular}{|c|c|}
\hline Locais de desenvolvimento do Atletismo & Objetivo \\
\hline CF de treinamento de Deodoro & Rendimento \\
\hline CF de treinamento de Jacarepaguá & Rendimento \\
\hline CT de Atletismo do Paraná (Cascavel) & Formação e rendimento \\
\hline CT de Itamonte & Rendimento \\
\hline AMAN (Exército Nacional) & Rendimento \\
\hline CT Altitude de Itatiaia & Rendimento \\
\hline Centro de Formação Olímpica do Nordeste & Formação \\
\hline CT de Campinas & Formação e rendimento \\
\hline CT Bragança Paulista (antiga equipe Rede) & Rendimento \\
\hline Centro Paraolímpico Brasileiro & Formação e rendimento \\
\hline CT Vila Olímpica & Formação e rendimento \\
\hline CT Santos Dumont & Formação \\
\hline Estádio Ícaro de Castro - Ibirapuera & Formação e rendimento \\
\hline Vila Olímpica de Maringá & Formaçáo e rendimento \\
\hline SESI Uberlândia e Blumenau & Formação e rendimento \\
\hline CT do Distrito Federal/SESI & Formação \\
\hline SOGIPA/Procempa & Rendimento \\
\hline CEFAN/Unifa & Rendimento \\
\hline CEPEUSP/E.C. Pinheiros & Rendimento \\
\hline ESEFEX (Exército Nacional) & Rendimento \\
\hline Arena CAIXA/São Bernardo do Campo & Formação e rendimento \\
\hline CETE & Formação e rendimento \\
\hline CEAR/Campinas/Orcampi/Unimed & Formação e rendimento \\
\hline UNIFOR & Rendimento \\
\hline UF de Lavras & Formação e rendimento \\
\hline CT da UFMG & Formação e rendimento \\
\hline UF do Maranhão & Formaçáo e rendimento \\
\hline
\end{tabular}

Identificou-se a partir desta notícia, outras pistas construídas com ajuda, do ME via Rede Nacional de Treinamento e dos governos municipais e estaduais, a saber: Vila Olímpica de Maringá (entregue em 2009); Arena Caixa de São Bernardo do Campo; Centro Esportivo Santos Dumont em Recife (entregue em 2013); Universidade Federal de Juiz de Fora; Universidade de São Paulo; CETE de Porto Alegre; e da cidade do Rio de Janeiro: Universidade da Força Aérea (UNIFA); Centro de Capacitação Física do Exército; e Centro de Educação Física Almirante Adalberto Nunes (pista reformada em 2011) ${ }^{30-34}$.

No entanto, não identificou-se nenhuma informação precisa com relação aos valores que serão gastos para mantê-las ou, ainda, se existe um projeto de manutenção via governamental ou via entidade privada. O portal Brasil 2016, site oficial dos Jogos Olímpicos do Rio de Janeiro, reporta o valor de manutenção anual de algumas estruturas utilizadas nos Jogos do Rio, como o Centro Olímpico de Tênis e de Esportes Aquáticos. O valor de manutenção gira em torno de $5 \%$ do valor total de cada estrutura, ou seja, o responsável pela manutenção pode chegar a gastar anualmente em torno de $\mathrm{R} \$ 10$ milhóes para manter uma dessas estruturas supracitadas em condiçôes de uso $^{26}$. Se aproximar essa lógica
Nota. Siglas das instituições foram detalhadas no decorrer do texto 
para as recentes pistas de atletismo construídas no país e levando em consideração o valor médio (aproximadamente $\mathrm{R} \$ 5$ milhóes) de construçáo de cada pista, seriam necessários 500 mil reais para manutenção anual de cada uma.

Segundo Mazzei et al. ${ }^{46}$, afirmam que o investimento em centros de treinamento, por meio de açóes de infraestrutura esportiva específica, é um dos fatores que podem possibilitar o desenvolvimento do esporte em médio e longo prazo em um país. Para os autores, os investimentos incluem os passos de construção, manutenção e adequação de estruturas esportivas pontuais, a falta de um destes passos pode atrapalhar o desenvolvimento esportivo.

A partir da busca documental, foi elaborado o QUADRO 2 com a intenção de revelar o objetivo das estruturas de atletismo. Para os autores Hong, Wu e XIONG ${ }^{19}$, isso deve fazer parte da estratégia esportiva de um país. Devido a dificuldade em encontrar fontes que revelem o real objetivo da implementaçáo das pistas, foi possível deduzir que as universidades federais, na sua maioria (92.8\%), a princípio devem focar na formação esportiva. Pode-se afirmar que alguns Complexos Federais (Centro de Cascavel, Fortaleza) poderão focar no rendimento esportivo, assim como, os Centros Nacionais e Regionais de Atletismo (Bragança Paulista/ SP, Lavras/MG) diagnosticados - apoiados pela CBAt -, e as principais instituiçóes já mencionadas neste estudo, como SOGIPA, Esporte Clube Pinheiros, B3 Atletismo e Orcampi.

Atualmente, as instalaçóes que ajudarão a determinar uma Rede Nacional de Atletismo estão presentes em universidades públicas de todas as regiōes do Brasil, em clubes, em complexos multiesportivos, em instalaçóes militares, municipais, estaduais, federais e em parcerias com a Confederação Brasileira de Atletismo.

O atletismo demonstra ser um esporte no Brasil que possui e também possuirá (muitos espaços estão em construção) boa estrutura física, ao contrário do que o senso comum acredita, deste ser um esporte com pouca estrutura física e, ainda, sem qualidade. As novas instalaçóes oficiais (Classes 1 e 2) de atletismo que atualmente existem no país, podem gerar um sentimento de bem estar, de orgulho e de comprometimento dos diversos agentes esportivos envolvidos (técnicos, atletas, gestores) em tais estruturas, com um trabalho sério e que traga diversos benefícios para o esporte em questão desenvolver-se entre os melhores do cenário mundial.

Porém, à medida que as pistas foram diagnosticadas neste estudo, quase não foram constatadas informaçóes documentais a respeito dos objetivos das mesmas. Ou também, se possuem projetos para a iniciação esportiva, parcerias com escolas, clubes de atletismo, ou projetos para o alto rendimento, tampouco foram identificadas informações sobre a implementação em equipamentos esportivos.

O presente estudo revelou que o espaço de prática de atletismo, em diferentes níveis do esporte, se encontra diversificado entre as capitais estaduais, com as cidades interioranas. Pode-se afirmar que estas últimas com uma presença maior entre as 20 melhores equipes do país por categoria. $\mathrm{Na}$ análise geral (a partir dos resultados dos 4203 atletas e 325 entidades identificadas no periodo pesquisado), há uma concentração maior, tanto de instituições, estruturas físicas $(37 \%)$ e resultados dos atletas $(60,6 \%)$ na regiáo sudeste, mas sem deixar de ter uma distribuição geográfica interessante (em cidades do Norte, Nordeste e Centro-Oeste) da prática desse esporte.

Sugere-se o que é necessário pensar: como utilizar da melhor maneira possível os espaços esportivos de atletismo aqui apresentados, para que ocorra o desenvolvimento dessa modalidade no país (mais participação, aumentar a oferta de talentos, seleção de atletas e melhores resultados). Esses achados servem como um auxílio, no sentido de melhorar a efetividade dos recursos públicos aplicados nos setores de formação de atletas e de rendimento esportivo.

Embora existam autores que discutam sobre a instalação e a gestão de estruturas esportivas no país, pode-se notar a ausência de estudos específicos sobre pistas de atletismo. Este estudo-de mapeamento, local, regional e nacional das instalaçóes esportivas e entidades que desenvolvem o atletismo competitivo no Brasil - pode ser apontado como precursor na modalidade investigada e como complementação para essa pesquisa, surgem outras possibilidades de estudos. Por exemplo, investigar a opiniâo dos principais gestores e treinadores esportivos do atletismo a respeito desta temática e como os atletas das principais instituiçóes aqui apresentadas, são detectados e/ou selecionados. 


\title{
Notas
}

a. Competições de nível internacional são realizadas em pistas Classes 1 ou 2, ou seja, possuem todas as recomendaçóes sugeridas pela IAAF, por exemplo, o piso sintético da pista deve possuir Certificado de Aprovaçáo da IAAF.

b. A equipe B3 Atletismo é a antiga BMF\&BOVESPA. Em 30 de março de 2017, passou a ser chamada de B3 Atletismo. Porém, em fevereiro de 2018, a equipe foi extinta, encerrou as atividades no esporte profissional. Disponível em http://www1.folha.uol.com.br/esporte/2018/01/1950672-maior-clube-de-atletismo-do-pais-b3-encerra-as-atividades-apos-30-anos.shtml.

c. Convênio no 761283/2011. Disponível no site do Portal de Convênios - Sistema de Gestão de Convênios e Contratos de Repasse (SICONV). Disponível em http://portal.convenios.gov.br/acesso-livre. Neste portal, é possível verificar diversos documentos: plano de ação, valores pagos para equipamentos esportivos e profissionais que atuaram nos Centros esportivos.

d. O SICONV, é a iniciativa do Governo Federal responsável por todo o ciclo de vida dos convênios, contratos de repasse e termos de parceria, no qual são registrados os atos, desde a formalização da proposta até a prestação de contas final.

\begin{abstract}
This study, in terms of purposes, is qualitative and quantitative in nature and, in terms of means, documentary research is used to obtain the data. Its main objective was to identify the recent physical structures of Brazilian athletics, its objectives and the geographic distribution of the main entities promoting this sport between the years of 2013 and 2016. Documental information was obtained through sports and governmental sites. A data collection was carried out on the website of the Brazilian Athletics Confederation (CBAt) of the ranking of the best athletes between the years of 2013 and 2016. The qualitative analysis was performed based on the precepts of the Bardin Content Analysis method and the quantitative through the IBM SPSS Statistics for Mac, version 20.0 program. Participated in this survey, during the period mentioned, 4203 athletes of athletics and their respective institutions. The results showed that there is a greater concentration of the physical sports structures destined for sports initiation as well as income in the regions of greater economic development of the country (South and Southeast), but still have an interesting geographical distribution, in some cities of the North, Northeast and Central-West regions. It is worth noting that there are initiatives through the construction, remodeling and equipping of Athletics facilities. It was verified that the physical structure of this modality is present in: public universities, clubs, military installations, multisport complexes, municipal facilities, state, federal, National Centers, Regional and Local. But few of them offer sports equipment for sports performance. In short, the findings of this study help the country to better define the objectives towards the Brazilian athletics.
\end{abstract}

KEYwords: Track Field; Physical structure; Sports institutions; Sports facilities.

\section{Referências}

1. Rees T, Hardy L, Gullich A, Abernethy B, Côté J, Woodman T, Montgomery H, Laing S, Warr C. The Great British Medalists Project: a review of current knowledge on the development of the World's Best Sporting Talent. Sports Med. 2016;46:1041-1058.

2. Green M, Oakley B. Elite Sport Development system and playng to win: uniformity and diversity in international approaches. Leis Stud. 2001;20:247-2267.

3. Digel H. The context $\mathrm{f}$ talent identification and promotion: a comparison of nations. New Stud Athl. 2002;17:13-26. 
4. Green M, Holihan B. Advocacy coalitions and elite sport policy change in Canada and the United Kingdom. Int Rev Sociol Sport. 2004;39:87-403.

5. Digel H. Development Spotlight - Brazil. New Stud Athl. 2011;26:131-134.

6. Truyens J, De Bosscher V, Heyndels B, Westerbeek H. A resource-based perspective on countries' competitive advantage in elite athletics. Int J Sport Policy Politics. 2014;6:459-489.

7. Hollings SC, Mallett CJ, Hume PA. The transition from elite junior track and field athlete to successful senior athlete: why some do, why others don't. Int J Sports Sci Coach. 2014;9:457-471.

8. Huxlei DJ, O'Connor D, Bennie A. Olympic and World Championship track and field athletes' experiences during the specialising and investment stages of development: a qualitative study with Australian male and female representatives. Qual Res Sport, Exec Health. 2017;10:256-272.

9. Côté J, Gilbert W. An integrative definition of coaching effectiveness and expertise. Int J Sports Sci Coach. 2009;4:307323.

10. Houlihan B, Green M. Comparative elite sports development. Systens sctrutures and public policy. London: Elsevier. 2008.

11. De Bosscher V, De Knop P, Van Bottenbrug S, Bingham J. Explaining international sporting success: an international comparison of elite sport systems and policies in six countries. Sport Manag Rev. 2009;12:113-36.

12. Green M. Changing policy priorities for sport in England: the emergence of elite sport development as a key policy concern. Leis Stud. 2004;23:365-85.

13. Meira TB, Bastos FC. Estrutura organizacional esportiva. In. Böhme MTS, editor. Esporte infanto-juvenil: treinamento a longo prazo - talento esportivo. São Paulo: Phorte. 2001.

14. Houlihan B, Green M. The changing status of school sport and physical education: explaining policy change. Sport Educ Soc. 2006;11.

15. International Association of Athletics Federations. [homepage]. Certification System. [citado 12 jan 2018]. Disponível em: file://Users/andrefelipecaregnato/Downloads/IAAF\%20CERTIFICATES\%20-\%20Certified\%20Athletics\%20 Facilities\%20(1).pdf

16. Confederação Brasileira de Atletismo. [homepage]. Estatísticas. Medalhas. São Paulo. CBAt. 2017. [citado 1 fev 2017 ]. Disponível em: http://www.cbat.org.br/estatisticas/medalhas.asp

17. Confederação Brasileira de Atletismo. [homepage]. Atletismo do Brasil supera metas nos Jogos do Rio 2016. São Paulo. CBAt. 2016. [citado 2 nov 2016]. Disponível em: http://www.cbat.org.br/noticias/noticia.asp?news=8846.

18. Ferreira R. Estudo Comparativo de alguns Sistemas Esportivos nacionais visando um Contributo para o Brasil. Políticas para o Esporte de Alto Rendimento. São Paulo. 2007.

19. Hong F, Wu P, Xiong H. Beijing ambitions: an analysis of the Chinese sports system and its olympic strategy for the 2008 Olympic Games. Inte J Hist. 2005;22:510-529.

20. Ziemainz H, Gulbin J. Talentselection, identification, development exemplified in the Australian. Talent Search Programme. New Stud Ath. 2002;17:27-32.

21. Ministério do Esporte. Rede Nacional de Treinamento. Brasília. 2016. [citado 11 set 2017]. Disponível em http:// www.esporte.gov.br/index.php/institucional/alto-rendimento/rede-nacional-de-treinamento

22. Gil AC. Como elaborar Projetos de Pesquisa. São Paulo: Atlas S.A. 6o Edição. 2008.

23. Confederação Brasileira de Atletismo. São Paulo. CBAt. 2016. Rankings. [citado 10 jan 2017]. Disponível em http:// www.cbat.org.br/estatisticas/ranking_outros_anos.asp

24. Estadão. Esportes. [homepage]. Fabiana Murer inaugura Centro de Treinamento em São Caetano do Sul. 2012. [citado 12 jan. 2016]. Disponível em: http://esportes.estadao.com.br/noticias/geral,fabiana-murer-inaugura-centro-de-treinamento-em-sao-caetano-do-sul,868786

25. Brasil 2016. [homepage]. Começam obras de preparação do Complexo Esportivo de Deodoro para o Rio 2016. 2014. [citado 1 fev 2016]. Disponível em: http://www.brasil2016.gov.br/pt-br/noticias/comecam-obras-de-preparacao-do-complexo-esportivo-de-deodoro-para-o-rio-2016

26. Brasil 2016. [homepage]. Região Barra. 2017. [citado 5 dez 2017]. Disponível em: http://www.brasil2016.gov.br/ pt-br/megaeventos/paraolimpiadas/instalacoes/barra

27. International Association of Athletics Federations. [homepage]. 2015. Mondotrack ws: the new Mondo track previewed at the IAAF World Championships Beijing 2015. [citado 12 mar 2017]. Disponível em: https://www.iaaf.org/news/ press-release/mondotrack-ws.

28. Confederaçáo Brasileira de Atletismo. CBAt e ME tratam dos Centros Nacionais de Treinamento de Atletismo. São Paulo. 
CBAt. 2015. [citado 12 jun 2016]. Disponível em: http://www.cbat.org.br/noticias/noticia.asp?news=7987\&back=S

29. Ministério do Esporte. Ministério do Esporte da primeiro passo para a construção do centro de altitude no Brasil. Brasília. 2008. [citado 11 nov 2016]. Disponível em: http://esporte.gov.br/index.php/noticias/24-lista-noticias/39749-ministerio-do-esporte-da-primeiro-passo-para-a-construcao-do-centro-de-altitude-no-brasil

30. Portal de Transparência. Convênios. 2015. [citado 2 jan 2015. Disponível em: http://www.portaltransparencia.gov. $\mathrm{br} /$ convenios $/$ convenioslista.asp? $\mathrm{uf}=\mathrm{rs} \&$ tipoconsulta $=1 \&$ codorgao $=51000 \&$ orgao $=\& \operatorname{codmunicipio}=8801 \& \mathrm{municip}$ io= \&periodo

31. Confederação Brasileira de Atletismo. CBAt realiza primeiro camping na Rede Nacional de Treinamento. São Paulo. CBAt. 2017. [citado 2 out 2017]. Disponível em: http://www.cbat.org.br/noticias/noticia.asp?news=9037

32. Portal de Transparência. Preparação de Atletas. Atletismo. 2015. [citado 4 dez 2015]. Disponível em: http://www. portaldatransparencia.gov.br/

33. Gestâo Esporte. [homepage]. A gestão de instalação esportiva e o estádio Célio de Barros. 2015. [citado 20 jan 2016]. Disponível em: http://gestaoesporte.com.br/novidade/a-gestao-de-instalacoes-esportivas-e-o-estadio-celio-de-barros

34. Ministério do Esporte. Ministério do Esporte investe mais de R 70 milhóes em 15 novas pistas de atletismo. Brasília. 2015. [citado 23 jan 2016]. Disponível em: http://www.esporte.gov.br/index.php/noticias/24-lista-noticias/50262-ministerio-do-esporte-investe-mais-de-r-70-milhoes-em-15-novas-pistas-de-atletismo-pelo-pais

35. Brasil. Ata de homologação das propostas selecionadas para formalização de convênios encaminhados de acordo com a chamada pública no 01/2012 da SNEAR. Brasília. DF.

36. Confederação Brasileira de Atletismo. São Paulo. CBAt. 2016. UFLA está pronta para ser um centro regional da RNT. [citado 12 jan 2017]. Disponível em: http://www.cbat.org.br/noticias/noticia.asp?news=9032\&back=S

37. Mezzadri FM, Moraes e Silva M, Cavichiolli FR. Brazil. In: Kristiansen E, Parent MM, Houlihan B. Elite youth sports policy and management: a comparative analysis. Abingdon: Routledge. 2016.

38. Matthiesen SQ, Silva MFG, Silva ACL. Atletismo na escola. Motriz. 2008;14:96-104.

39. Hastie AH, Calderon A, Rolim JR., Guarino AJ. The development of skill and knowledge during a sport education season of track and field athletics. Res Q Exerc Sport. 2013;84:336-344.

40. Brito N, Fonseca AM, Rolim R. Os melhores atletas nos escalóes de formaçáo seráo igualmente os melhores atletas no escalão sénior? Análise centrada nos rankings femininos das diferentes disciplinas do Atletismo ao longo das últimas duas décadas em Portugal. Rev Port Ciênc Desp. 2004;4:17-28.

41. Vasconcelos-Raposo J, Lázaro J, Mota M, Fernandes H. Caracterização dos níveis de ansiedade em praticantes de atletismo. Motricidade. 2007;3:298-314.

42. Brasil. (2011). Lei no 12.395 de 16 de março de 2011. Altera as Leis nos 9.615, de 24 de março de 1998, que institui normas gerais sobre desporto, e 10.891, de 9 de julho de 2004, que institui a Bolsa-Atleta; cria os Programas Atleta Pódio e Cidade Esportiva; revoga a Lei no 6.354, de 2 de setembro de 1976; e dá outras providências. 2011. Brasília.

43. Giglio SS, Rubio K. Futebol Profissional: o mercado e as práticas de liberdade. Rev Bras Educ Fís Esporte. 2013;27:387400.

44. Fin A. Running with the kenyans: discovering the secrets of the fastest people on Earth. London: Faber and Faber. 2012. 45. Jarvier F, Sikes M. Running as a resource of hope? Voices from Eldoret. Rev Afrc Political Econ. 2012;39:629-644.

46. Mazzei LC, Bastos FC, Ferreira RL, Böhme MTS. Centros de treinamento esportivo para o esporte de alto rendimento no Brasil: um estudo preliminar. Rev Min Educ Fís Edição Especial. 2012;1:1575-1584.

ENDEREÇO

André Felipe Caregnato

Pedro Demeterco, 1091

81530-320 - Curitiba - PR - Brasil E-mail: andre.caregnato@hotmail.com
Submetido: $18 / 01 / 2016$

1a. Revisão: a23/04/2018

2a. Revisão: 14/ 01/ 2019

Aceito: 24/ 05/ 2021 